\title{
Structure and Microhardness of Steel Samples after Pulse Plasma Flows Processing*
}

\author{
Anuar Zhukeshov, Asylgul Gabdullina, Assem Amrenova, Svetlana Pak \\ Department of Plasma Physics, Science Research Institute of Experimental and Theoretical Physics, Almaty, Kazakhstan. \\ Email: zhukeshov@physics.kz \\ Received May $15^{\text {th }}, 2013$; revised June $17^{\text {th }}, 2013$; accepted June $30^{\text {th }}, 2013$ \\ Copyright (C) 2013 Anuar Zhukeshov et al. This is an open access article distributed under the Creative Commons Attribution License, \\ which permits unrestricted use, distribution, and reproduction in any medium, provided the original work is properly cited.
}

\begin{abstract}
The phase structure of surfaces of steel samples, modified by pulse plasma processing, was analyzed using XRD and metallographic methods. It has been shown, that after pulse plasma processing under different conditions a modified structure consisting of three new phases, including austenite, iron nitride and carbide, is formed. The dependence of phase transition and microhardness on plasma flow parameters has been studied. A sharp decrease in the dimensions of ferrite crystallites after the impact of plasma flow is observed. The main purpose of hardening of common steel samples is formation of nano-dimension ferrite with oriented iron carbide on grains.
\end{abstract}

Keywords: Component; Formatting; Style; Styling; Insert

\section{Introduction}

The pulse plasma processing, as one of the ways of highenergy impact on surfaces of materials, is a promising method of creation of materials with given properties. This method enables us to combine thermal influence of hot plasma with doping by the particles of the plasma flow. Today, the most important applications of pulsed plasma processing (PPP) are: formation of p-n junctions, doping of steels with nitrogen combined with simultaneous surface recrystallization, preparation of mixed surface layers on metals and ceramics, formation of surface alloys, and a pretreatment (cleaning) of metals and ceramics for the PVD coatings [1-4].

One of the most important technological applications of the PPP process is hardening of metal surface. In [5] the authors presented the results of investigations of properties of the modified surface layer treated by nitrogen plasma flows, with parameters varied in a wide range (several devices were used): time duration $\tau=1-100 \mu \mathrm{s}$, plasma flow energy density $E=2-30 \mathrm{~J} / \mathrm{cm}^{2}$, energy of particles $\mathrm{W}=0.4-10 \mathrm{keV}$. Based on the experimental results, the authors concluded that changes in the surface structure do not noticeably depend on changes in particle energy and pulse duration, but depend on the energy density applied to the sample surface. However, these investigations do not fully describe physical processes in

*The work performed as part of government grant of Ministry of Science and Education of Kazakhstan Republic. Grant No 3П6/2013. the materials.

As it is shown in [6], the pulse plasma accelerator "CPA-30" with a coaxial system of electrodes provides high power supply $(\mathrm{C}=75 \mu \mathrm{F}, \mathrm{U}=30 \mathrm{kV})$ for melting the surface of metal alloys after plasma flow treatment. However, physical properties of processed materials change only under certain regimes of plasma flow, as high density of the energy flow can cause not only improvements of properties, but also destruction of the material. Therefore, the correct choice of processing regimes plays an important role in targeted treatment of material surface. In the "continuously filling" regime [7], at constant initial gas pressure in the working chamber, the plasma density varies over a wide range, and the energy has maximum $\mathrm{E}-50 \mathrm{~J} / \mathrm{cm}^{2}$ at $\mathrm{P}=0.05-0.1$ Torr of the initial gas pressure.

Thus, for metal alloys such as common and stainless steels, the basic result of plasma treatment is hardening. Therefore, it is necessary to study physical properties of subsurface layers and the detailed structure of materials. In this paper we study the influence of plasma processing regimes on changes in the structure and, hence, steel hardness. The energy density of a one-time impact was chosen as the basic parameter of processing.

\section{Experiment}

\subsection{The Samples and Equipment}

Samples of ST-3 common steel with $0.3 \mathrm{At}_{\%} \mathrm{C}$ with sizes 
$15 \times 15 \times 4 \mathrm{~mm}$ have been prepared and polishing by abrasive paper ${ }^{\#} 2000$. After these, the surface of samples was electrochemical polishing. The samples were processed at different energy densities of air plasma on the. The process curried out on CPU-30 accelerator at discharge current $100-250 \mathrm{kA}$, duration of half period about 6 - $7 \mu \mathrm{s}$. The diameter of the plasma flow (about 8 $\mathrm{cm})$ was greater than the dimension of samples. The samples placed perpendicular to plasma flow at distance $7 \mathrm{~cm}$ from end of electrode. The X-ray diffraction analysis (XRD) of the processed samples was carried out on "D8 Advance" diffractometer, the microhardness was measured on the metallurgical microscope "Metaval". The lattice parameters of materials were determined by a specialized program of the diffractometer [8]. We will further consider the results of structural studies of the common steel treated by plasma flows in a continuous mode. In this mode we got the values of changes in the structure of materials after single and multiple plasma treatment for different values of the initial pressure of $0.04-0.5$ Torr.

\subsection{The Phase Changes in Material}

The parameters of common steel, one time processing, are given in Table 1. The basis of the initial sample of common steel is ferrite $\mathrm{Fe}_{\alpha}$ with the space-centered lattice and the lattice parameter $\mathrm{a}=2.8691 \pm 0.0005 \mathrm{~A}$. The basic phase of the sample has coherent diffraction areas (crystallite size) of a dimension $\mathrm{L}=1160 \mathrm{~A}$. An analysis of the XRD data shows that the single treatment causes structural and phase transformations of the material.

The basic structure of common steel is converted into a two-phase solution. One of the phases is a solid $\alpha$-solution-ferrite, the lattice parameter is not actually changing. Pulsed plasma treatment leads to the formation of the second phase of the face centered lattice, which corresponds to the austenite $(\gamma-\mathrm{Fe})$. The specific feature of processing for all samples is the presence of a new austenite phase. As it is shown in Table 1, the maximal crystallite size L of austenite is contained in the sample \#5, processed by $32 \mathrm{~J} / \mathrm{cm}^{2}$. For example, a detailed phase diagram of the processed sample ${ }^{\#} 5$ is given in Figure 1. The obtained results show that the influence of the plasma flow on the structural parameters does not have a trivial character. The dimension of ferrite crystallites strongly depends on plasma energy varies in the range 40 $50 \mathrm{~J} / \mathrm{cm}^{2}$. The austenitic phase reaches a weak maximum at an energy density of $32 \mathrm{~J} / \mathrm{cm}^{2}$, when the maximal crystallite quantity and maximal dimensions of austenite crystallites are observed.

Further, we will consider the multiple plasma impact on the surface of this material. The quantity of multiple treatment $\mathrm{N}$ and given new phases shown in Table 2.

When the surface of common steel is treated by sev-
Table 1. The single processing samles data.

\begin{tabular}{ccccc}
\hline Sample & $\begin{array}{c}\text { Q, } \\
\text { J/cm }\end{array}$ & $\begin{array}{c}\text { Ferrite } \\
\text { L, A }\end{array}$ & $\begin{array}{c}\text { Austenite } \\
\text { L, A }\end{array}$ & $\begin{array}{c}\text { Austenite parameter, } \\
\pm 0.0005 \mathrm{~A}\end{array}$ \\
\hline Initial & 0 & 1160 & - & - \\
№ 3 & 16 & 730 & 175 & 36,172 \\
№ 4 & 22 & 610 & 160 & 36,141 \\
№ 5 & 32 & 460 & 240 & 36,212 \\
№ 7 & 44 & 115 & 110 & 36,184 \\
№ 9 & 48 & 145 & 140 & 36,223 \\
\hline
\end{tabular}

Table 2. The multiple processing samples data.

\begin{tabular}{|c|c|c|c|c|c|}
\hline Sample & $\mathrm{N}$ & $\begin{array}{c}Q, \\
\mathrm{~J} / \mathrm{cm}^{2}\end{array}$ & $\begin{array}{c}\text { Lattice } \\
\text { parameter a, A }\end{array}$ & Phase & $\mathrm{L}, \mathrm{A}$ \\
\hline \multirow{3}{*}{ № 1} & \multirow{3}{*}{5} & \multirow{3}{*}{25} & $3.6217 \pm 0.011$ & $\mathrm{Fe}-\gamma$ & 195 \\
\hline & & & $2.056 \pm 0.001$ & $\mathrm{FeC}$ & \\
\hline & & & $2.8630 \pm 0.0004$ & $\mathrm{Fe}$ & 380 \\
\hline \multirow{3}{*}{ № 2} & \multirow{3}{*}{10} & \multirow{3}{*}{28} & $3.6254 \pm 0.0011$ & $\mathrm{Fe}-\gamma$ & 210 \\
\hline & & & $2.055 \pm 0.001$ & $\mathrm{FeC}$ & \\
\hline & & & $2.8605 \pm 0.0003$ & $\mathrm{Fe}$ & 395 \\
\hline \multirow{3}{*}{ № 3} & \multirow{3}{*}{20} & \multirow{3}{*}{26} & $9.0760 \pm 0.0046$ & $\mathrm{Fe}_{24} \mathrm{~N}_{10}$ & \\
\hline & & & $3.6217 \pm 0.0011$ & $\mathrm{Fe}-\gamma$ & 180 \\
\hline & & & $2.8607 \pm 0.0005$ & $\mathrm{Fe}$ & 275 \\
\hline \multirow{3}{*}{ № 4} & \multirow{3}{*}{30} & \multirow{3}{*}{25} & $9.1082 \pm 0.0046$ & $\mathrm{Fe}_{24} \mathrm{~N}_{10}$ & \\
\hline & & & $3.6295 \pm 0.0018$ & $\mathrm{Fe}-\gamma$ & 145 \\
\hline & & & $2.8603 \pm 0.0009$ & $\mathrm{Fe}$ & 200 \\
\hline
\end{tabular}

eral plasma pulses at $\mathrm{P}=0.1$ Torr, a further increase in the intensity of formation of $\gamma$-Fe is observed (Figure 2).

Processing of the 5 and 10 pulses in the two-phase solution of $\alpha-\mathrm{Fe}(\mathrm{a}=2.8603 \pm 0.0009 \mathrm{~A})$ and $\gamma-\mathrm{Fe}(\mathrm{a}=$ $3.6295 \pm 0.0018$ A) revealed the presence of a small amount of martensite $\mathrm{FeC}$. Further, processing of the 20-th and 30-th pulse led to formation of iron nitride $\mathrm{Fe}_{24} \mathrm{~N}_{10}$. Nitride was observed in the diffraction broadened diffuse lines (samples $\left.{ }^{\#} 3,4\right)$. The nitride intensity peaks in the sample number 4 treated 30 times were higher than the peaks for the sample number 3 , which was treated 2 times by 20 plasma pulses. In addition, the lattice parameter of iron nitride in the samples ${ }^{\#} 3$, 4 differed from the ideal sample: a $=92,150$ A, which could be caused by the deformation of nitride lattice.

\subsection{The Surface Changes of Material}

Table 1 shows the results of determination of crystallite size of ferrite and austenite in the steel samples after processing, using Scherer's method. It can be seen that the crystallite size of ferrite decreases and the crystallite size of $\gamma$-Fe remains unchanged with increasing $\mathrm{Q}$, and increasing $\mathrm{N}$, but in the case of a single treatment this 


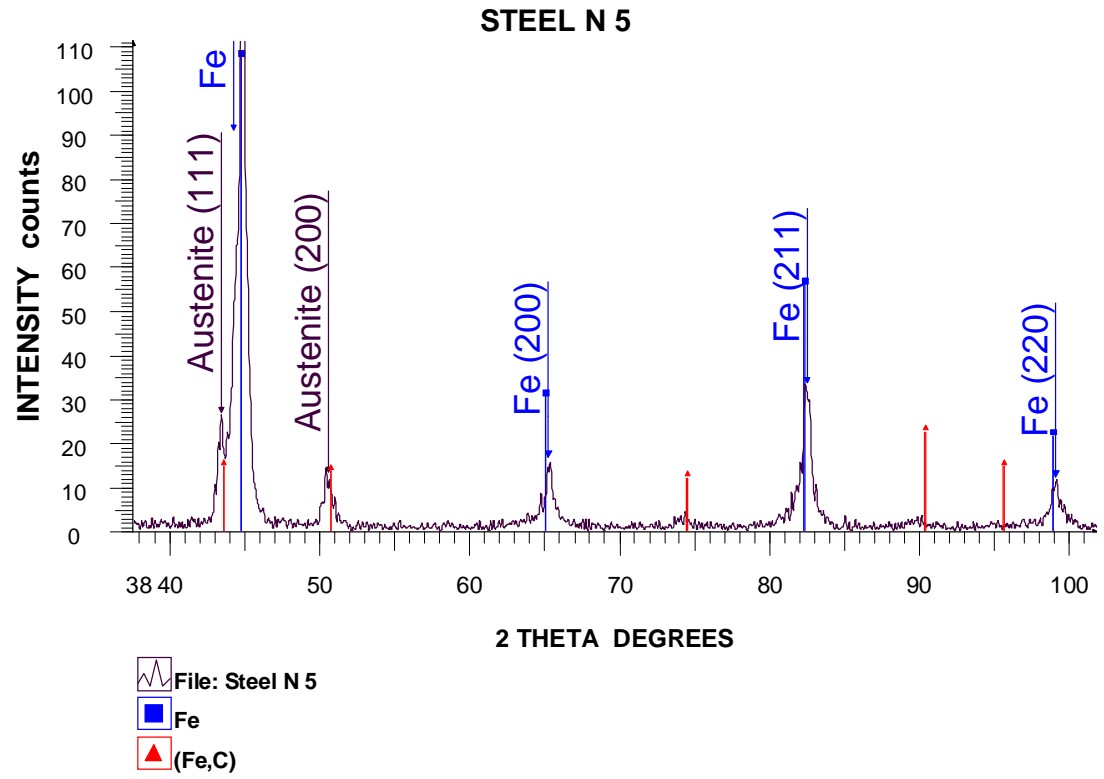

Figure 1. Diffraction pattern of sample ${ }^{\#} 5$.

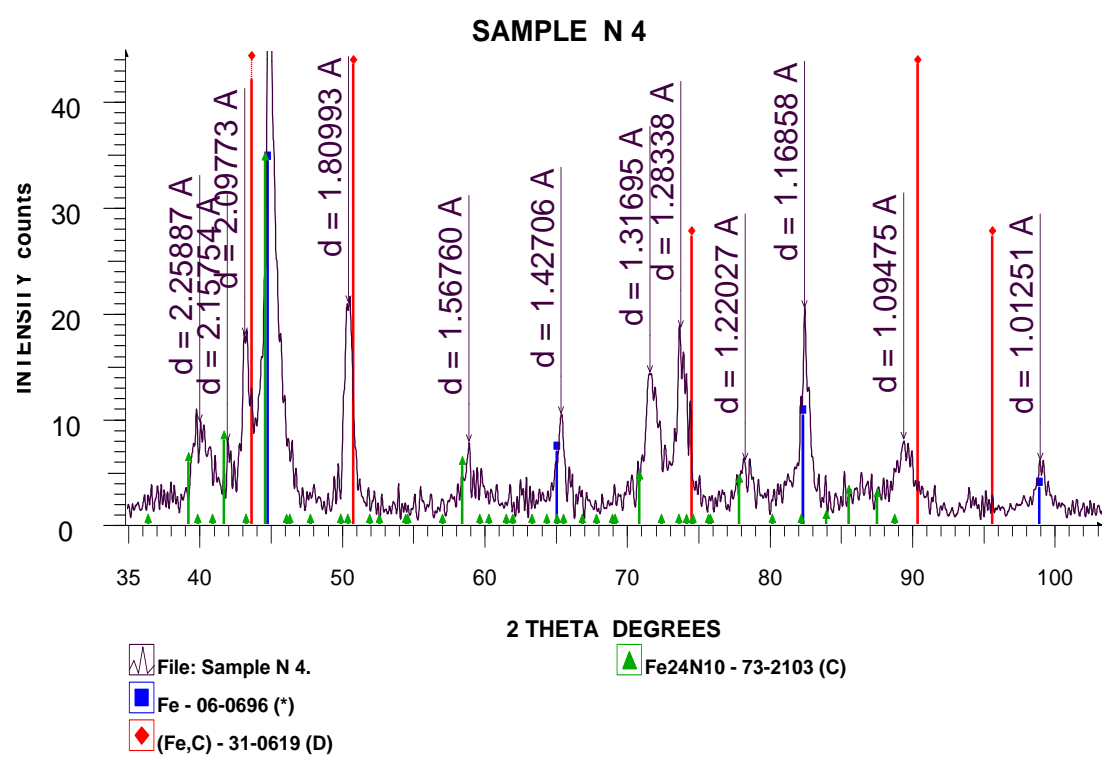

Figure 2. Diffraction pattern of sample ${ }^{\#} 4$.

effect is more pronounced.

These results are in good agreement with those obtained by the SEM. The change in the grain size can be clearly seen in the photographs of the microstructure of the surface after etching for grain visualization (Figure 3), and may be caused by the dissolution of large grains and increase in the number of dispersion structures (Figures 3(d)-(f)) at higher $Q$ values. In this pictures the samples ${ }^{\#}$ 3, 4, 5 from Table 1 given at a, b, c $\times 400$ and d, e, $\mathrm{f} \times 2000$ amplification, respectively.

The stage of formation of the two-phase solution after plasma treatment at the residual air pressure in the CPU-30 chamber is clearly seen in Figure 4 . The figure shows that the two-phase solution is formed as precipitates at the grain boundaries even at low $\mathrm{Q}(\mathrm{Q}$ for the sample number 1 is $5 \mathrm{~J} / \mathrm{cm}^{2}$ ), and the increase in the energy density of the plasma flow passes through a series of successive stages. Phase transformation reaches its maximum after multiple plasma treatment.

Austenitizing promotes heating of the material surface, which is also typical of electronic beam processing. As a result, a large amount of the carbide source material is dissolved and transformed into austenite with high carbon content. The surface profile of the common steel sample after plasma treatment was obtained by atomic force microscopy (Figure 5). In picture the columnar 


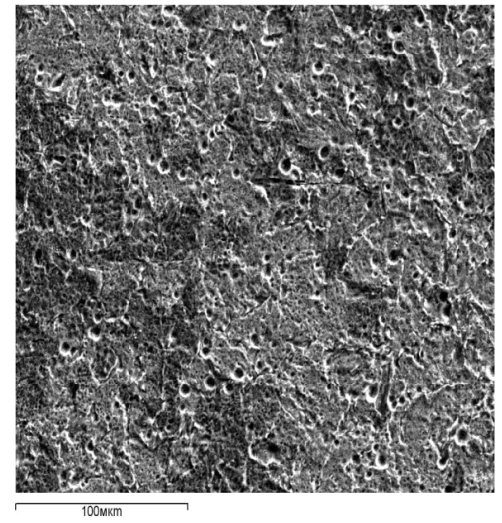

(a)

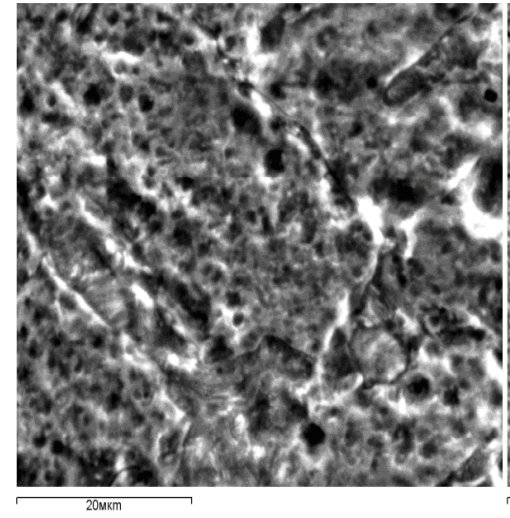

(d)

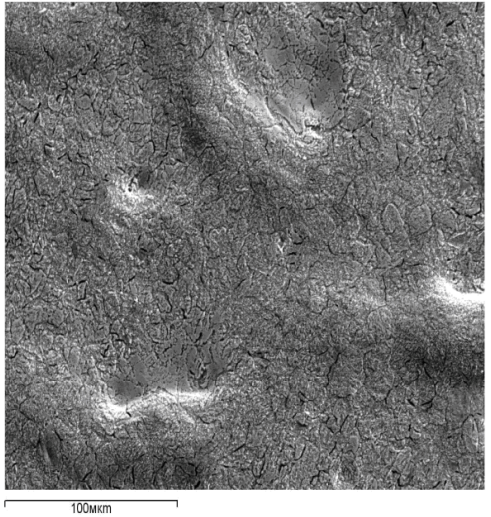

(b)

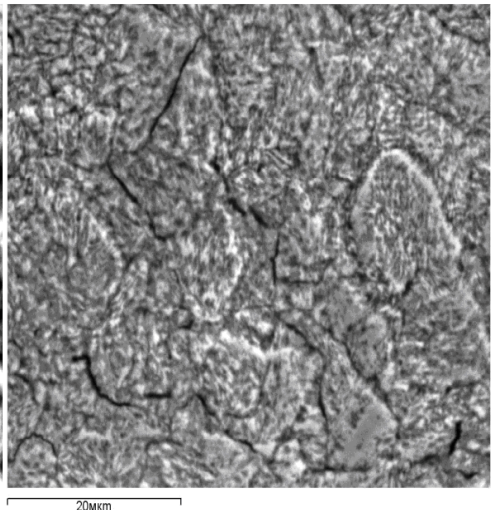

(e)

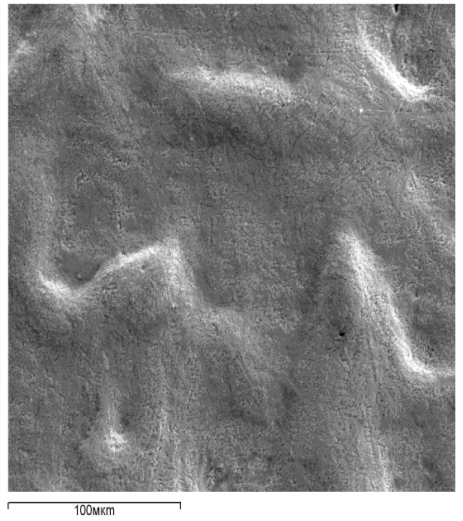

(c)

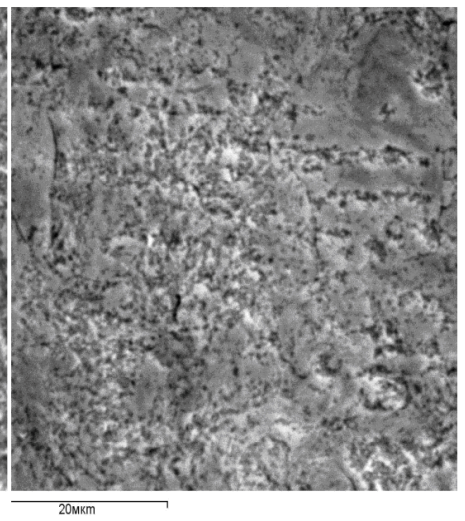

(f)

Figure 3. The structure of the surface of steel samples after air plasma treatment at $\mathbf{P}=0.04$ Torr, $\mathbf{N}=1$.

grain structure is observed, which is characteristic of the formation of $\mathrm{FeC}$ phase.

\subsection{The Properties Changes of Material}

Figure 6(a) shows the influence of the sample structure on the microhardness of the material. The microhardness of the processed samples changes proportionally to the energy density, however, the same regularity is observed. As it is shown in Figure 6(a), for the first group of samples $\left({ }^{\#} 1,2\right)$ the value of microhardness does not change considerably at $2000 \mathrm{MpA}$. For the second group (samples ${ }^{\#} 3$ - 6) the microhardness increases two-fold (4000 $\mathrm{MPa}$ ), and for the third group (samples ${ }^{\#} 7,8$ ) it increases by more than three-fold (7000 MPa). However, only the third group is of practical interest because it has high hardness in spite of greater crystallite dimensions. In general, the proportionality of the energy is observed for all samples. Thus, there is an optimal value of energy density in area $20-44 \mathrm{~J} / \mathrm{cm}^{2}$, at which the microhardness of common steel is rather high $\sim 4000 \mathrm{MPa}$ and crystallites with minimal size $115 \mathrm{~nm}$ are formed. At low energy below $20 \mathrm{~J} / \mathrm{cm}^{2}$ no hardening is observed, and at high energies crystallite sizes increase.
HV measurements of the common steel surface after repeated treatment showed that the first 5 of 10 pulses increased hardness, and further processing stabilized the hardening process (Figure 6(b)) due to completion of the austenitization and formation of the martensite phase and iron nitride.

\section{Conclusions}

The influence of plasma processing regimes on changes in the structure and, as a consequence, on steel hardness is studied. Under the action of plasma flows, physical and mechanical properties of common steel change differently. In case of a single treatment, hardening of the material is proportional to the energy density, but after 5 pulses the saturation stage is reached. The single treatment causes structural and phase transformations of the material. The original structure of common steel $\mathrm{Fe}_{\alpha}$ with the volume centered lattice is converted into a multiphase solution. A significant feature of processing for all samples is the presence of a new austenite phase at energies up to $40 \mathrm{~J} / \mathrm{cm}^{2}$ and a nitride phase at higher energies and multiple treatments. At high speed crystallization process a large amount of carbide is dissolved and transformed 

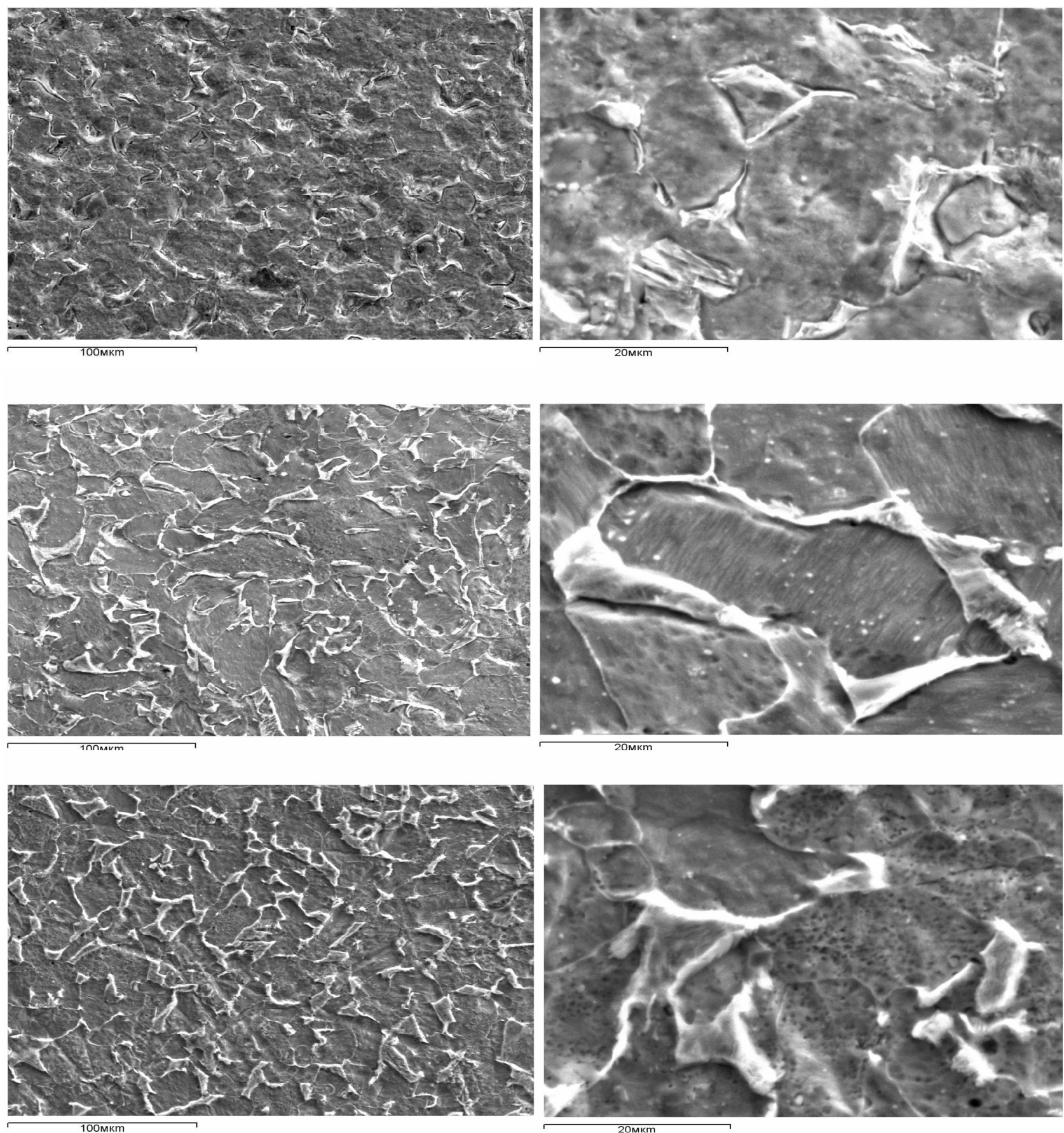

Figure 4. Formation of a two-phase solution after treatment $\left(P=0,5\right.$ Torr, $N=1$, samples $\left.{ }^{\#} 1,2,3\right)$.

into austenite with high carbon content. In the AFM pictures a columnar grain structure is observed, which is indicative of the formation of the high carbide (martensite) phase, formed due to quick cooling of the material. The carbon atoms, probably, diffusion from material bulk to surface and participate in new phase creation process.

The ferrite crystallite size decreases and the size of $\gamma$-Fe does not change with the increase of energy density of plasma, falling on surface, and number of processing
$\mathrm{N}$, but in the case of a single treatment it is more pronounced. The change of the grain size may be caused by the dissolution of large grains and higher dispersion under influence of plasma. It is shown that the two-phase solution on subsurface area is formed in the form of precipitates at the grain boundaries. Phase transformation reaches its maximum after multiple plasma treatments. The microhardness of the material also depends on surface structure. The microhardness of processed samples 


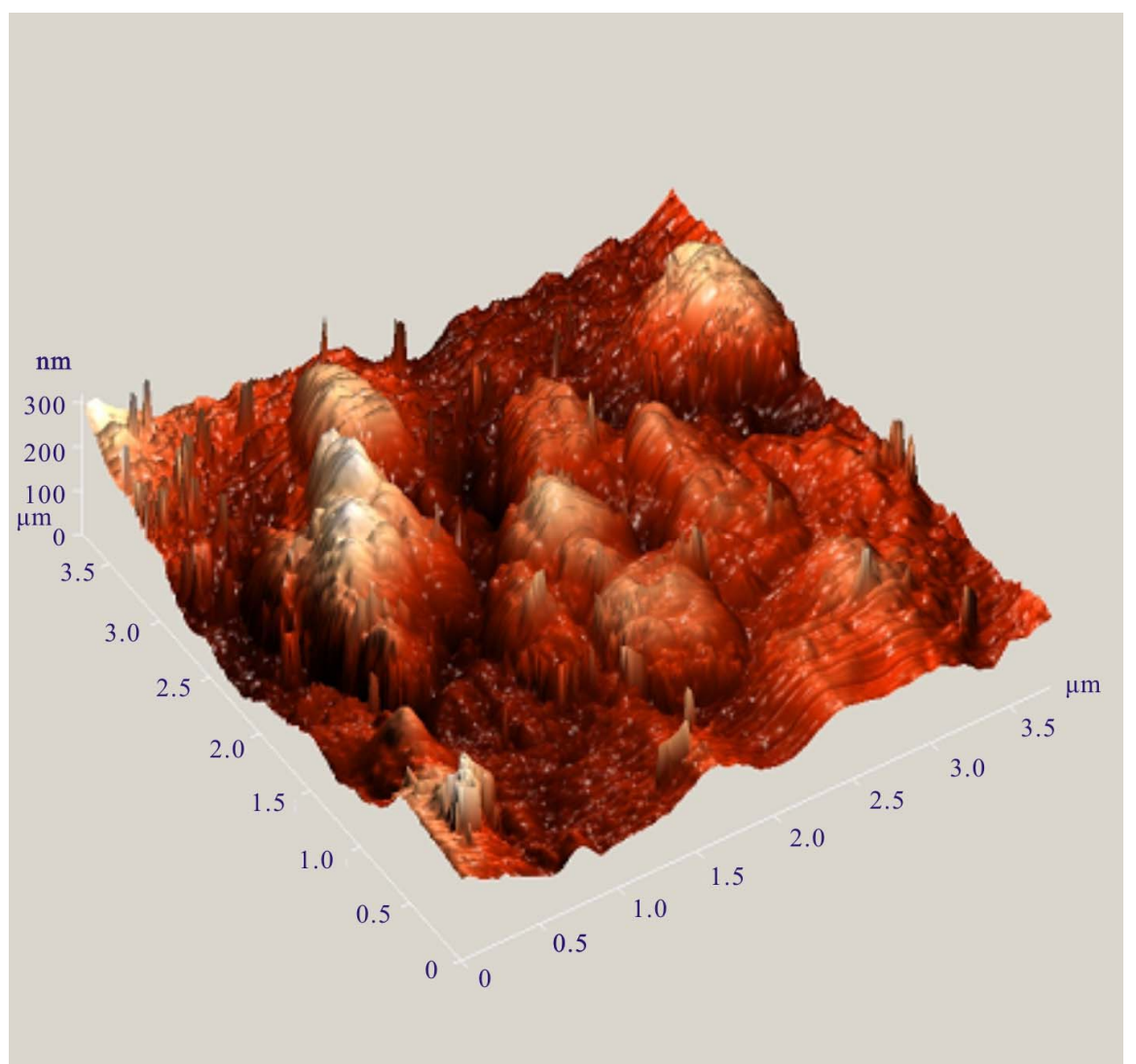

Figure 5. AFM image of steel surface after plasma treatment.

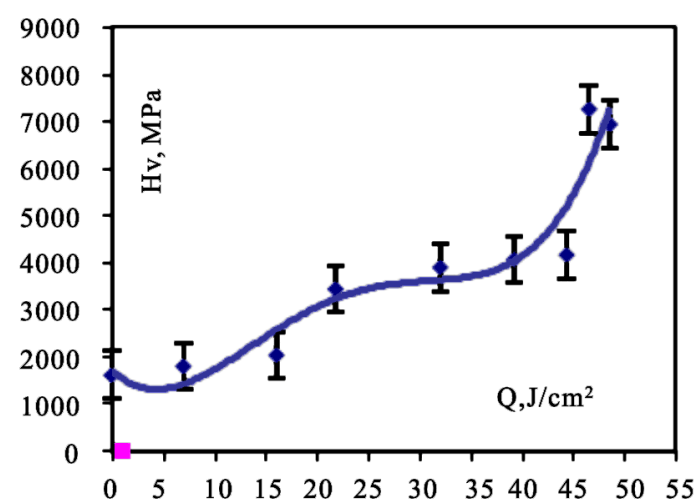

(a)

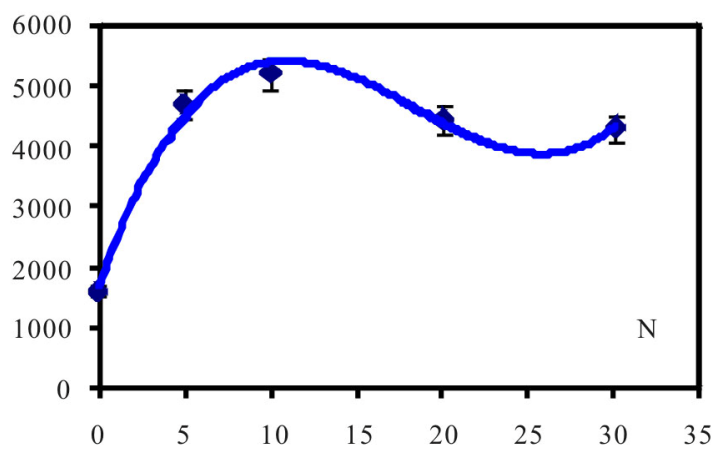

(b)

Figure 6. Microhardness as a function of energy density for single (a) and multiple (b) processed samples.

changes proportionally to energy density, however at multiple treatment it reached its maximum after 5 treatments.

Therefore, we are assume, that significant reducing of $\alpha$-Fe crystallites size after pulsed plasma processing and the concentration of carbon atoms on boundaries of crystal grains is the main reason of surface hardening of material. The phenomena may be used for creation of surface hardening technology with using of pulsed plasma treatment.

\section{Acknowledgements}

The work performed as part of government grant of Ministry of Science and Education of Kazakhstan Republic.

\section{REFERENCES}

[1] V. V. Chebotarev, I. E. Garkusha, A. M. Bovda, et al., "Application of Pulsed Plasma Accelerators for Surface modification," Nukleonika, Vol. 46, No. 1, 2001, pp. 27-30. 
[2] Z. Peng, H. Miao and W. Wang, "Hard and Wear-Resistant Titanium Nitride Films for Ceramic Cutting Tools by Pulsed High Energy Density Plasma," Surface and Coatings Technology, Vol. 166. No. 2-3, 2003, pp. 183-188. doi:10.1016/S0257-8972(02)00776-4

[3] J. Langner, J. Piekoszewski, J. Stanisiawski and Z. Werner, "Present Status and Prospects of Research in SINS on the Modification of Surface Properties by Pulsed Plasma Streams," Nukleonika, Vol. 45, No. 3, 2000, pp. 193-197.

[4] V. M. Anishik and V. V. Uglov, "Modification of Instrumental Materials by Ion and Plasma Beams," BSU, Minsk, 2003, 191 p.

[5] V. V. Chebotarev, I. E. Garkusha, J. Langner, et al., "Surface Structure Changes Induced by Pulsed Plasma
Streams Processing," Problems of Atomic Science and Technology, Vol. 3, No. 3, 1999, pp. 273-275.

[6] F. B. Baimbetov, A. M. Zhukeshov and A. U. Amrenova, "Dynamics of Plasma Flow Formation in a Pulsed Accelerator Operating at a Constant Pressure," Technical Physics Letters, Vol. 33, No. 1, 2007, pp. 77-79. doi:10.1134/S106378500701021X

[7] A. M. Zhukeshov, "Plasma Flow Formation in a Pulse Plasma Accelerator in Continuous Filling Regime," Plasma Devices and Operations, Vol. 17, No. 1, 2009, pp. 73-81. doi:10.1080/10519990802703319

[8] A. Zhukeshov, "Plasma Diagnostics in a Pulsed Accelerator Used for Material Processing," Journal of Physics. Conference Series, Vol. 63, No. 01201, 2007. 